\title{
CONSUMISMO PRECOCE E MÍDIA: DISCURSOS PUBLICITÁRIOS DE UM CANAL TELEVISIVO INFANTIL
}

PRECOCIOUS CONSUMERISM AND MEDIA: PUBLICITY DISCOURSES OF A TV CHANNEL FOR CHILDREN

CONSUMISMO TEMPRANO Y MEDIOS SOCIALES: DISCURSOS DE PUBLICIDAD DE UN CANAL DE TELEVISIÓN PARA NIÑOS

\author{
Camila Marques Silva Daher \\ Giselle Braga de Aquino*
}

\begin{abstract}
RESUMO
A sociedade contemporânea é marcada pelo consumo e, nessa organização, a criança tem seu lugar de consumidora reservado pela mídia, principalmente a televisiva. A tevê é algo bastante presente na vida das crianças e um importante divulgador de publicidade infantil. Este trabalho identificou os discursos usados pela publicidade de um canal televisivo infantil na tentativa de persuadir a criança e seus cuidadores. Para a realização da pesquisa, foram gravadas e transcritas as peças publicitárias desse canal, e os textos resultantes da transcrição foram submetidos à análise do discurso. Para análise e discussão, o material foi organizado em duas categorias: "felicidade e status por meio do consumo" e "reprodução de papéis de gênero". Os principais resultados apontaram que os discursos apresentaram os produtos como fórmula para a felicidade e o reforço aos papéis de gênero socialmente construídos pela estratégia de exposição de seus produtos.
\end{abstract}

Palavras-chave: Consumismo. Infância. Publicidade.

\begin{abstract}
The contemporary society is marked by consumption, and in this organization, children have their places as consumers reserved by the media, mostly the TV media. The TV is something very present in children's life and an important spreader of infantile publicity. This work identifies the publicity discourses of TV channel for children trying to persuade them and their caregivers. The development of the research required the recording and transcription of advertising pieces of this channel and the texts resulting from the transcription were submitted to a Discourse Analysis. In order to carry out the analysis and debate, the material was organized in two
\end{abstract}

Texto recebido em 23 de maio de 2016 e aprovado para publicação em 20 de setembro de 2016.

Acadêmica no curso de Bacharelado em Psicologia pela Faculdade de Minas (Faminas), Campus Muriaé-MG. E-mail: camiladaher@hotmail.com.

** Professora e coordenadora do Curso de Psicologia da Faminas, Campus Muriaé-MG, professora no Curso de Pedagogia da Universidade do Estado de Minas Gerais (UEMG), Campus Leopoldina-MG. E-mail: gi07ba@yahoo.com.br. 
categories: "happiness and status through consumption" and "reproduction of gender papers". The main results have pointed out that the discourses presented the products as a formula for happiness and the reinforcement to the gender roles built socially through the strategy of the exposition of its products.

Keywords: Consumption. Childhood. Publicity.

\section{RESUMEN}

La sociedad contemporánea está marcada por el consumo y, en esta organización, el niño tiene su lugar de consumo reservado por los medios de comunicación, especialmente la televisión. La TV es algo muy presente en la vida de ellos y un importante promotor de la publicidad infantil. Este trabajo identifica los discursos utilizados por la publicidad de un canal de televisión para niños, en un intento de persuadirles y, también, a sus cuidadores. Para realizar el estudio, se grabaron y transcribieron los anuncios de ese canal y, los textos resultantes de la transcripción fueron sometidos al análisis del discurso. Para el análisis y la discusión, el material fue segmentado en dos categorías: "Felicidad y el estatus a través del consumo" y "Reproducción de los roles de género". Los principales resultados mostraron que los discursos presentaban los productos como fórmula para la felicidad y, el fortalecimiento de los roles de género socialmente construidos a través de la estrategia de exposición de sus productos.

Palabras clave: Consumismo. Infancia. Publicidad.

\section{INTRODUÇÃO}

$\mathrm{O}$ consumismo é uma prática de consumo excessivo que vem se destacando, de forma preocupante, na atualidade. $\mathrm{Na}$ sociedade pós-moderna, nomeada por Bauman (1999, p. 87), como "sociedade do consumo", consumir é a condição central. Atualmente, na organização do consumo, este é encarado como uma fórmula para a felicidade, não sendo apenas uma questão de sobrevivência. O autor destaca que é preciso formar consumidores para que a sociedade contemporânea se organize e flua (Bauman, 1999; 2008). O "ter" marca lugares e papéis sociais, o que, para Debord (1997), significa que a mercadoria assume um papel de dominação das relações humanas, construindo uma "sociedade do espetáculo". Nesta, os consumidores são meros espectadores do mercado, e as relações, por sua vez, tornam-se superficiais, baseadas no que se tem e no que se aparenta ter. É o produto mediando a vida do homem, o "ter" se apropriando do "ser", e não o contrário. 
O consumo que não está pautado em uma necessidade essencial, de acordo com Debord (1997), cria uma necessidade ilusória que somente pode ser satisfeita pela compra e que, para Bauman (1999; 2008), faz fluir a "sociedade do consumo", configurando o chamado consumismo (Santos, 2010). Percebe-se que a maioria das pessoas está inclusa nessa lógica do consumo, no sentido de desejar, mas nem todos podem efetivar esse desejo, o que demarca um processo de exclusão.

Assim, as famílias de classe média, englobando, nesta análise, as famílias trabalhadoras que tiveram seu poder de compra expandido nos últimos anos, no Brasil, e não apenas as que se enquadram em um "antigo" conceito de classe média, que envolvia exclusivamente as camadas burguesas da sociedade, passaram a ter mais acesso às mídias, tecnologias e produtos, revelando-se um público lucrativo ao mercado da publicidade (Pochmann, 2014). As crianças, especialmente, são cada vez mais permeadas por expectativas e marcadores sociais, mesmo antes de nascer, revelando-se alvos em potencial para a publicidade. Dessa forma, o público infantil é inserido, desde muito cedo, na lógica do consumo, sendo influenciado pela prática do consumismo infantil (Dexheimer \& Bacha, 2011; Galindo \& Assolini, 2008; Pereira, Cerdeira, Andreiuolo, \& Souza, 2005).

Através dos séculos, a infância sai da indiferença, ganha um lugar de destaque e ocupa uma posição social que é objeto de várias áreas de saber (Ariès, 2006; Castro, 1998; Pereira \& Souza, 1998). Assim, os pais e cuidadores entram em contato com uma série de discursos "especializados" que difundem uma suposta normalização dos cuidados infantis.

Tal fato pode ser exemplificado pela imensa oferta de produtos infantis existentes no mercado. As crianças, como seres sociais, apropriam-se desse mundo que lhes é apresentado, no qual consumir constrói e permeia relações, e em que os anúncios oferecem aparências e posições sociais, sendo preciso comprar para alcançar algo que se deseja (Debord, 1997; Martineli \& Moína, 2009).

Nesse sentido, a televisão, por ser um veículo presente nas residências, salas de espera, lojas e em diversos outros ambientes, tornou-se um importante divulgador de publicidade voltada ao público infantil (Salgado, Pereira, \& Souza, 2005). Uma série de discursos são transmitidos e reproduzidos, pela publicidade televisiva, na tentativa de persuadir a criança. Porém os detentores do poder de compra são os cuidadores, e não as crianças, ou seja, apenas adultos podem, de fato, efetivar a compra. Logo, o consumismo precoce é perpassado, em muitos momentos, pelo desejo dos pais.

Para atingir os cuidadores ou pais, a publicidade infantil pode utilizar duas estratégias. Na primeira delas, a própria criança aparece como ferramenta ou 
personagem nos anúncios. A criança fica nessa posição como forma de atingir diretamente os pais ou cuidadores, a fim de que esses efetivem a compra do produto, como nas propagandas de fraldas e compostos lácteos. $\mathrm{Na}$ segunda, a criança surge como alvo, a mensagem atinge, de forma direta, o público infantil (Sampaio, 2004; 2009). Neste último caso, a publicidade induz a criança a ser mediadora entre o produto anunciado e os pais ou responsáveis. Portanto ela é influenciada a solicitar-lhes o produto, muitas vezes, de forma exaustiva, e utiliza como estratégia o nag factor, traduzido como "fator amolação" (Linn, 2006). Para alcançar o público infantil e os pais ou responsáveis, a publicidade ainda insere nas peças elementos como "humor, música, rimas, sílabas repetitivas, jingles e personagens de desenhos animados" (Oliveira \& Real, 2011, p. 5).

As crianças têm passado uma grande parcela de tempo em frente à tevê, tendo grande acesso à gama publicitária. A esse respeito, deve ser considerado que, nessa fase do desenvolvimento, há certa carência de experiências, existindo uma relação muito tênue e de influência mútua entre imaginação e realidade (Vigotski, 2014). O caráter, a sociabilidade e a afetividade também estão em construção, por esse motivo, a influência da mídia televisiva é enorme (Silva \& Leite, 2013). O consumismo infantil é, então, uma prática que pode influenciar ou intensificar alguns problemas, como a obesidade infantil, o consumo de drogas, violência e estresse na família, formação de valores materialistas, erotização precoce e diminuição de brincadeiras criativas, e um consequente desequilíbrio no meio social, ambiental e econômico (Brasil, 2014; Conselho Federal de Psicologia [CFP], 2015).

Fonseca (2014) utiliza-se dos mesmos argumentos do CFP (2008; 2014; 2015), ao afirmar que é claro o abuso da publicidade em relação à criança. Esse público não pode ser considerado passivo, mas é influenciável, pois se encontra em plena formação cognitiva, afetiva, de identidade e autonomia, tendo dificuldades de se perceber induzido ao consumo, ou seja, diferenciar o conteúdo comercial da programação regular. A publicidade acaba então explorando tal condição de imaturidade e vulnerabilidade. Nesse sentido, vale mencionar que existem algumas normas protetivas e preventivas, no âmbito jurídico brasileiro, relacionadas a essa questão.

A Constituição Federal de 1988, em seu artigo 227, e o Estatuto da Criança e do Adolescente (ECA) (Lei no 8.069/1990), em seu primeiro artigo, destacam o dever da família, da sociedade e do Estado em oferecer atenção integral à criança, respeitá-la e protegê-la de qualquer crueldade, opressão, discriminação ou violência (Constituição da República Federativa do Brasil, 1988; Lei no 8.069/1990; Fonseca, 2014). Outro instrumento legal que diz respeito especificamente à publicidade infantil é o Código de Defesa do Consumidor 
(Lei no 8.078/1990), em seus artigos 36, 37 e 38, que proíbe a publicidade de difícil identificação, abusiva ou enganosa e responsabiliza os patrocinadores às informaçōes publicitárias veiculadas.

Em relação à regulamentação da publicidade infantil, esta, no Brasil, é realizada por um órgão autorregulamentador (ou seja, regido por seus próprios membros, profissionais da publicidade), o Conselho Nacional de Autorregulamentação Publicitária (Conar). Esse órgão surgiu como aplicação do Código Brasileiro de Autorregulamentação Publicitária, criado também pelos próprios profissionais da publicidade, em 1978 (Giacomini Filho, 1992). Segundo o Conar, sua missão é "Impedir que a publicidade enganosa ou abusiva cause constrangimento ao consumidor ou a empresas e defender a liberdade de expressão comercial" (Conselho Nacional de Autorregulamentação Publicitária, 2013).

No dia 13 de março de 2014, foi aprovada a Resolução no 163 do Conselho Nacional dos Direitos da Criança e do Adolescente (Conanda), que considera ilegal qualquer tipo de publicidade e a comunicação mercadológica dirigida a crianças e adolescentes com intenção de induzir ao consumo (Fonseca, 2014). Porém, mesmo com a resolução aprovada, os anunciantes insistem em veicular a publicidade infantil, descumprindo os aparatos legais. Por isso, demarca-se a necessidade de fiscalização (Instituto Alana, 2014).

Apesar dos poucos progressos jurídicos em relação ao tema no Brasil, em 2016, uma ação civil pública movida pelo Ministério Público, como representação do Instituto Alana, contra uma campanha publicitária infantil marcou o início do ano: pela primeira vez, uma decisão jurídica foi tomada considerando abusiva e ilegal a publicidade infantil, baseando-se nos aparatos jurídicos brasileiros. A empresa responsável pelo anúncio foi condenada a pagar indenização pelos danos causados (Apelação 0342384- 90.2009.8.26.0000, 2013; Brasil, 2016). Ainda assim, a publicidade direcionada às crianças continua sendo veiculada na tevê, tanto em canais abertos quanto em fechados.

O CFP se posiciona ante a temática em defesa do pressuposto de que a publicidade infantil é abusiva e deve ter sua veiculação proibida. Pela participação em audiências públicas e a publicação de uma cartilha intitulada Contribuição da Psicologia para o fim da publicidade dirigida à criança (CFP, 2008), o Conselho argumenta a favor da aprovação do Projeto de Lei no 702/2011, que propõe a restrição da veiculação publicitária de produtos infantis. O CFP afirma que os aparatos jurídicos existentes não têm eficácia, sendo insuficientes na proteção contra a abusividade da publicidade infantil (CFP, 2008; 2014; 2015).

É importante ressaltar ainda que, em países como França, Alemanha, Canadá e Itália, existem aparatos jurídicos que se mostram mais eficazes que os existentes 
no Brasil, e que, em países europeus e nos Estados Unidos, além do aparato jurídico, existe também uma inciativa interessante que ainda não se discute no contexto brasileiro: projetos de educação para as mídias, que visam a fornecer às crianças instrumentos que possibilitem o desenvolvimento de um olhar mais crítico em relação ao conteúdo a que são expostos pela televisão (Capparelli et al., 2007).

Surge, então, a necessidade de uma análise que questione o modo como se desenrola a persuasão da publicidade infantil, quais fatores influenciam o consumismo desse público que está em condição de vulnerabilidade, dependência e em pleno desenvolvimento. Portanto se buscou, por este estudo, identificar as mensagens e estratégias que fundamentam e justificam os discursos usados pela publicidade televisiva infantil. Realizou-se uma análise da publicidade do canal infantil fechado Cartoon Network, pela metodologia de análise do discurso (Pêcheux, 2002).

Atualmente são escassas as produções, tratando dessa questão, de profissionais inseridos na área da Psicologia. Assim, é necessário iniciar e estimular análises e pesquisas norteadas por um olhar da Psicologia, por meio de um diálogo com a Sociologia e outras ciências, de forma a complementar as publicações científicas existentes, possibilitando novos questionamentos, caminhos e perspectivas.

O estudo focaliza especialmente, as famílias de classe média, com base no conceito utilizado por Pochmann (2014), já teorizado no texto. Porém, mesmo considerando o caráter de ascensão do grupo econômico que ocupava o que se chama de base da pirâmide social, identificado como classe média, o aspecto da exclusão não deve ser esquecido, afinal o poder de compra é limitado, não sendo possível ter tudo o que é ofertado pela publicidade.

\section{MÉTODOS}

\subsection{Descrição da pesquisa}

Para a realização da pesquisa, utilizou-se a gravação do conteúdo de um canal de programação infantil, a fim de analisar a publicidade dos intervalos comerciais. A gravação foi realizada durante cinco dias, por quatro horas diárias: entre os dias 10 e 14 de março de 2014, de segunda a sexta-feira, das oito horas da manhã até meio-dia.

A escolha do canal ocorreu pelo critério de conveniência, motivada principalmente pela idade do público-alvo, visto que a programação desse canal é direcionada a um público de variação de idade abrangente. Esse foi também 
o motivo para a gravação ser realizada no período matutino, horário em que a maioria das crianças, nessa faixa-etária, está em casa, visto que, na região em que o trabalho foi realizado, o horário de funcionamento das escolas infantis abrange amplamente o período vespertino.

Após a gravação das peças publicitárias, realizou-se a separação das propagandas com conteúdo mercadológico. Dessas peças foram eliminados dois comerciais, sendo selecionadas 21 propagandas. Tal eliminação justificase pela curta duração dessas peças e pela ausência de discursos que objetivem a persuasão do consumidor, sendo os produtos apenas anunciados nesses casos. Todas as propagandas que foram objeto desta análise foram transcritas na íntegra e submetidas à análise de discurso (Pêcheux, 2002).

$\mathrm{Na}$ figura 1, é apresentado o resumo de todas as peças publicitárias exibidas durante o período de gravação, sendo as 21 analisadas destacadas em negrito. Nele também se expõe o número de vezes em que a peça foi inserida na programação durante todo o período gravado, ou seja, durante os cinco dias da semana. 
Figura 1 - Apresentação das peças gravadas (em destaque, as que foram analisadas e a quantidade de inserções durante o período de gravação)

\begin{tabular}{|c|c|c|}
\hline PECA & DESCRIĊÄO & INSERCÁA \\
\hline 1 & Raspa Mix (DTC) - Raspadinha instantânea & 21 \\
\hline 2 & Lilica \& Tigor - Vestuário infantil & 15 \\
\hline 3 & Garagem S.A (Candide) - Brinquedo & 7 \\
\hline 4 & Barbie Segredo das Pérolas - Filme & 3 \\
\hline 5 & Fini-Balas & 3 \\
\hline 6 & Robo Fish (DTC) - Raspadinha Instantânea & 3 \\
\hline 7 & Beto Carrero World "Madagascar" - Parque de diversöes & 1 \\
\hline 8 & Kidy - Calcados infantis & 1 \\
\hline 9 & PBF - Escola de idiomas & 19 \\
\hline 10 & Rihappy - Loja de brinquedos & 12 \\
\hline 11 & Fisk - Escola de idiomas (Exibicão de duas pecas diferentes) & 11 \\
\hline 12 & Os Mixels (Cartoon Network) - Jogo para celular & 5 \\
\hline 13 & Yázigi - Escola de idiomas & 5 \\
\hline 14 & Danoninho (Danone) - Iogurte & 10 \\
\hline 15 & Enfagrow - Composto lácteo & 9 \\
\hline 16 & Tang - Refresco em pó & 9 \\
\hline 17 & Pampers (P\&G) - Fralda & 3 \\
\hline 18 & Nutren Kids - Composto lácteo & 2 \\
\hline 19 & Ben 10 - Nova linha de produtos & 9 \\
\hline 20 & Cupcake Surpresa (Estrela)-Boneca & 7 \\
\hline 21 & Picadilly For Girls - Linha de calcados infantil & 6 \\
\hline 22 & Anúncios internos do canal & 87 \\
\hline 23 & Anúncio de outros canais (TNT e Boomerang) & 7 \\
\hline 24 & Campanhas (Chega de Bullying e Internet Segura) & 7 \\
\hline 25 & Rio Quente Resorts - Resort & 3 \\
\hline 26 & Mococa Chocolate (Mococa) - Bebida lactea & 2 \\
\hline 27 & PBKids - Loja de brinquedos & 1 \\
\hline
\end{tabular}

Fonte: elaborado pelas autoras.

Essa análise foi baseada não somente nas narrações e diálogos (Pêcheux, 2002), mas também na ambientação, nas cores, jingles entre outros aspectos constituintes das propagandas. Identificou-se então os discursos mais recorrentes, que apresentavam elementos específicos que se repetiam nas propagandas, o que resultou na categorização do material. Foram criadas duas categorias, "felicidade e status pelo consumo" e "reprodução de papéis de gênero", ambas divididas em duas subcategorias: a primeira, em "fantasia e diversão instantânea" e "poder e exclusão"; e a segunda, em "apelo à mãe moderna como responsável pelo cuidado dos filhos" e "meninas X meninos: estereótipos de gênero". 


\section{ANÁLISE E DISCUSSÃO DOS RESULTADOS}

A análise e discussão das propagandas por meio de suas categorias foi organizada pelo tipo de discurso principal apresentado em seu conteúdo. É importante ressaltar que todos os anúncios analisados foram direcionados aos cuidadores ou às próprias crianças e utilizaram elementos lúdicos que permeiam o imaginário infantil, sendo as crianças, assim, imersas em uma espécie de mundo infantil midiático transposto de significados criados pelo mercado (Buckingham, 2007).

\subsection{Felicidade e status pelo consumo}

Nesta categoria, são analisadas as mensagens estratégicas básicas por trás de todos os anúncios retratados nesta pesquisa. Tais questões aparecem mais claramente nas propagandas citadas. São as grandes ofertas que a publicidade infantil faz à criança e a seus cuidadores explícita ou implicitamente: a felicidade por meio do produto. Ou seja, para que a criança se divirta, ela precisa ter, precisa consumir. Um desejo, que pode ser até mesmo inútil ou inapropriado, é despertado, somente podendo ser satisfeito pela compra (CFP, 2008).

Emprega-se, como uma das principais estratégias, o lúdico, o famoso "faz de conta", aproveitando-se da frágil dependência entre imaginação e realidade (Vigotski, 2009). De acordo com Oliveira e Real (2011), isso costuma ser apresentado de modo bastante sutil mediante o uso de personagens, de músicas repetitivas, sílabas, humor e certas melodias, por exemplo. O uso de tais estratégias é uma unanimidade nas peças apresentadas.

É necessário citar uma questão que aparece também em todos os anúncios da pesquisa, sem exceções: a promessa de status. Norteando todas as mensagens publicitárias desse canal (um fato provavelmente influenciado por conta do público-alvo, que é a classe média), está o preceito de que, pela compra do produto, o consumidor (seja a própria criança ou os pais) estará numa posição privilegiada em relação às outras pessoas. Para que a criança seja feliz, bemsucedida, admirada, versátil, diferente, ela precisa ter os produtos ofertados pela publicidade.

Esse fator é explicitado por Bauman (1999; 2008), que diz da necessidade de transformar as pessoas em consumidoras, para que a organização social flua. Fato que dialoga com as reflexões de Debord (1997), ao tratar das aparências que os produtos geram num mundo em que o mercado dita o querer das pessoas: para que a criança "seja", para que ela se identifique com os outros, ela precisa "ter" o produto. Para o autor, o consumidor (neste caso, uma criança) torna-se alguém que compra ilusões. 
Por conta dos diferentes enfoques e estratégias das peças publicitárias inseridas nesta categoria, elas foram subdivididas: "fantasia e diversão instantânea" e "poder e exclusão". Tal divisão possibilita uma análise mais aprofundada, partindo dos principais discursos reproduzidos para justificar a felicidade e o status mediante o consumo. Na figura 2, são apresentados trechos das propagandas analisadas nesta categoria e sua relação com as respectivas subcategorias de análise.

\section{Figura 2 - Trechos das peças analisadas e relação com as subcategorias de análise relacionadas à categoria 3.1 (enumeração de peças referente à figura 1)}

\begin{tabular}{|c|c|c|}
\hline PEÇA & DESCRIÇÃO E TRECHOS ANALISADOS & CATEGORIA \\
\hline 1 & $\begin{array}{l}\text { Enquanto são retratadas imagens de crianças se divertindo com o produto, a narração acelerada anuncia: } \\
{[\ldots . .] \text { "Raspadinha instantânea é com o Raspa Mix! [...]. Em menos de dois minutos vocé terá deliciosa }} \\
\text { raspadinha instantânea! Demais! [...]. As opções são infinitas! Basta congelar, apertar e curtir! Raspa } \\
\text { Mix é da DTC, a marca da diversão." }\end{array}$ & 3.1.1 \\
\hline 2 & $\begin{array}{l}\text { Crianças pulando ao ar livre com roupas coloridas da marca em uma atmosfera de alegria. Ao fundo, a } \\
\text { vinheta: "Oh oh oh... Li-li-ca-ca-ca-ca-cá, Tigor, Ti-ti-ti-gor! Lilica, Lilica! Tigor, e o tigre, ha-ha-ha! Li- } \\
\text { li-ca-ca-ca-ca-cá, Tigor, Ti-ti-ti-gor! Lilica, Tigor!". }\end{array}$ & 3.1.1 \\
\hline 3 & $\begin{array}{l}\text { Enquanto são exibidas imagens do brinquedo, a narração anuncia: "Carros futuristas Garagem S.A, é mais } \\
\text { que diversão, é Candide!". }\end{array}$ & 3.1.1 \\
\hline 4 & $\begin{array}{l}\text { A tela exibe uma imagem da boneca: "Aguarde! Barbie vai mostrar como o poder das pérolas deixa tudo } \\
\text { mais lindo do que antes!". }\end{array}$ & 3.1.1 \\
\hline 5 & $\begin{array}{l}\text { Em uma floresta mágica, a bruxa se aproxima de uma casa colorida feita de doces: "Pó Nelsão, vocês } \\
\text { comeram o material de construção de novo! Como é que eu vou trazer o João e a Maria pra cá? Me } \\
\text { explica!" [...] Narração: "Fini, balas que tem sabores e modelos irresistiveis, de um jeito que combina } \\
\text { com você!" }\end{array}$ & 3.1.1 \\
\hline 6 & $\begin{array}{l}\text { Vinheta: "Robo Fish! Robo Fish, é só jogar na água pra ele nadar! ". Narração acelerada: [...] você ficará } \\
\text { surpreso ao ver quanto o Robo Fish parece real! [...]. Você pode brincar com ele em qualquer lugar! [...] } \\
\text { Ele nada muito sem parar um segundo! [...] Robo Fish é da DTC, a marca da diversão!" }\end{array}$ & 3.1.1 \\
\hline 7 & $\begin{array}{l}\text { Cenas de personagens e áreas temáticas são exibidas. Narração: "O Beto Carrero World preparou uma } \\
\text { grande surpresa! Para a diversão ficar completa, os seus personagens favoritos da Dreamworks ganharam } \\
\text { uma gigantesca área temática só para eles! Cheia de atrações, muita diversão" [...] }\end{array}$ & 3.1.1 \\
\hline 8 & $\begin{array}{l}\text { Crianças fantasiadas de heróis aparecem se divertindo em um cenário colorido e lúdico: "Kidy, Kidy, quero } \\
\text { Kidy pra mim! Confortável e saudável, quero Kidy pra mim! [...]. Me sinto livre pra brincar, pra correr, } \\
\text { pra pular! Kidv, Kidv, quero Kidv pra mim! ....]" }\end{array}$ & 3.1.1 \\
\hline 9 & $\begin{array}{l}\text { Animações com personagens e frases em inglês são exibidas: "Aprender outro idioma desde pequeno é } \\
\text { muito mais fácil, e a } P B F \text { é a melhor opção para quem quer aprender inglês a partir dos quatro anos. } \\
\text { Matricule já o seu filho! É desde pequeno que se aprende a falar inglês. Faça } P B F ! " \text {. }\end{array}$ & 3.1.2 \\
\hline 10 & $\begin{array}{l}\text { Na cena inicial e na cena final é exibida uma animação do mascote da loja jogando futebol com crianças: } \\
\text { "Começou o Festival Campeão Rihappy! Um festival de brinquedos com ofertas campeãs para você. [...]. } \\
\text { Não dá para perder! Festival Campeão Rihappy é uau!". }\end{array}$ & 3.1.2 \\
\hline 11 & $\begin{array}{l}\text { Propaganda l: A cena exibe uma adolescente em um carro acessando o conteúdo anunciado em seu tablet. } \\
\text { Diälogo com motorista: [...] "Demais esse conteúdo online do novo cyber Fisk! ". [...] Narração: "Falou } \\
\text { Fisk, falou tudo!". } \\
\text { Propaganda 2: "Oh, it's true! The Earth is blue!" - Garoto vestido de astronauta segurando um tablet com } \\
\text { o desenho do planeta terra. "O futuro do seu filho é como a imaginação dele: sem limites! Criança que fala } \\
\text { Fisk, fala tudo!". }\end{array}$ & 3.1.2 \\
\hline 12 & $\begin{array}{l}\text { Enquanto são exibidas imagens do jogo e de aparelhos eletrônicos, a narração anuncia: "Você já ouviu } \\
\text { falar dos Mixels? Não? Tudo bem, porque agora você tem a chance de viver como um deles em: Chamando } \\
\text { Todos os Mixels. [...] Chamando Todos os Mixels: disponivel para Iphone, Ipad, Ipod Touch e aparelhos } \\
\text { Android. Cartoon Network celular: quer jogar?". }\end{array}$ & 3.1.2 \\
\hline 13 & $\begin{array}{l}\text { Diálogo dos personagens (1,2 e 3) caracterizados como crianças em uma animação que retrata um quarto } \\
\text { infantil: } 1 \text { : "Eu nem acredito que a gente vai conhecer a Flórida! " } 2 \text { e 3: "Me neither! Yeah! " } 1: \text { "E o } \\
\text { que vocé quer fazer quando a gente chegar lá, Mary girl? " } 2 \text { : "Ah, eu vou conhecer todos os parques!" } \\
\text { 3: "E você, Faisca? " } 1 \text { : "Ah, eu quero tomar um banho de baleia! " } 2 \text { : "Você quer dizer banheira, né? } \\
\text { " 1: "Ah, vocês vão ver! "Muda-se de cenário, estando os personagens na Flórida. Uma baleia pula e os } \\
\text { molha: } 1,2 \text { e 3: "Awesome! "Narração: [...] Yázigi, você cidadão do mundo." }\end{array}$ & 3.1 .2 \\
\hline
\end{tabular}

Fonte: elaborado pelas autoras. 


\subsubsection{Fantasia e diversão instantânea}

O grande ponto em comum nesses anúncios é a atmosfera de diversão e felicidade, seja pela empolgação do narrador do Robo Fish, Beto Carrero e Raspamix, pelos sorrisos, músicas e pulos de liberdade em Lilica \& Tigor e Kidy, pela promessa de diversão de Garagem S.A., ou pelo mundo mágico de Barbie e Fini. Coincidindo com o que enfatiza Oliveira e Real (2011) a respeito dos mecanismos utilizados pela publicidade infantil: músicas, cores chamativas, sorrisos, ambientes fantásticos, jingles repetitivos e narração entusiasmada são as principais estratégias utilizadas.

Em Kidy, Fini, Beto Carrero e Barbie, um mundo de fantasia é ofertado à criança por meio do produto, tocando no frágil imaginário infantil. A publicidade, assim, explora uma questão que ainda não é nítida para a criança: a relação entre o que é real e o que é imaginação (Vigotski, 2009). Sarmento (2003) aponta que o imaginário infantil é uma forma de relação da criança com o mundo e que, psicologicamente, independentemente da abordagem teórica considerada, é comumente compreendido como uma forma de "preencher" sua concepção de mundo, visto que ainda carece de aspectos racionais de compreensão.

Dessa forma, a criança pode desejar a compra do produto, por acreditar neste como um modo de fazer parte daquele mundo fantástico que lhe foi apresentado. Esse aspecto pode ser ilustrado com este trecho da propaganda Barbie, Segredo das Pérolas: "Aguarde! Barbie vai mostrar como o poder das pérolas deixa tudo mais lindo do que antes!". Para uma criança, há grandes possibilidades de se acreditar que a personagem realmente exista e faça o que é prometido, pois não é explicitado o fato de a Barbie ser um personagem.

A promessa de diversão instantânea é nítida em Raspamix e Robo Fish, ambos da mesma marca. As mensagens são marcadas pela fala extremamente acelerada e entusiasmada do narrador. No anúncio do primeiro produto, este é apresentado como um item que, além de divertir a criança, fará com que ela faça um refresco de modo muito prático e rápido ("Em menos de dois minutos, você terá deliciosa raspadinha instantânea! Demais! [. . .] Basta congelar, apertar e curtir!"). O segundo é apresentado como um brinquedo que pode ser usado em qualquer ocasião e que possibilitará diversão rápida e prática ("Você pode brincar com ele em qualquer lugar! [. . . E Ele nada muito, sem parar um segundo! [. . . ] Robo Fish é da DTC, a marca da diversão!").

A estratégia, então, tem a mesma essência, reproduzindo que, no mundo contemporâneo, as pessoas precisam cada vez mais de praticidade, inclusive as crianças. Bauman (2001), ao falar da liquidez das relações, enfatiza o aspecto da 
busca cada vez mais emergente por rapidez, fluidez, devido à imprevisibilidade do mundo, a dinâmica das relações que está em constante transformação.

\subsubsection{Poder e exclusão}

Os anúncios apresentados nesta categoria contêm o seguinte discurso: a criança que adquirir o produto será detentora de um poder, o que reforça a lógica da ilusão ofertada pela mercadoria. É oferecido ao consumidor algo que não necessariamente satisfará uma necessidade, mas que apresenta uma promessa com caráter de aparência, criando e implantando nas crianças (e também nos cuidadores) a noção de que, obtendo o produto, a criança estará ou parecerá estar numa posição privilegiada (Debord, 1997).

A criação e reprodução de tal lógica faz com que haja uma mensagem de exclusão voltada à criança que não tem possibilidades de ter acesso ao produto anunciado. Esse processo é o tempo todo perpassado pelo desejo dos pais, afinal são os detentores do poder de compra. Portanto as propagandas analisadas apresentam mecanismos que vendem sua ideologia tanto para o público infantil quanto para o público de cuidadores.

Os pontos que mais se destacam nos anúncios são o idioma e a tecnologia. Nas propagandas das três escolas de idiomas apresentadas, existem falas ou palavras na língua inglesa sem a apresentação de uma tradução, fazendo com que crianças que não tenham conhecimento da língua não compreendam a mensagem. Cria-se, assim, certa relação de poder entre o detentor do conhecimento (no caso, conhecimento da língua inglesa) e a criança que não conhece (deve então consumir o produto oferecido para conhecer).

Ainda nos anúncios das escolas de idiomas e também no da loja de brinquedos, um ponto em comum é o direcionamento das mensagens. O desejo é despertado na criança por meio de estratégias que chamam sua atenção, como animações, frases imperativas e afirmativas ("Faça PBF!”), vinhetas repetitivas e crianças como protagonistas aparecem a todo o momento. Mas a responsabilidade de preparar o filho para o mundo e oferecer a ele o melhor é delegada aos pais no fim da propaganda, quando o narrador se dirige a eles, responsabilizando-os pela efetivação do consumo (PBF e Fisk). Porém a realização somente acontece quando esses pais têm condições para consumir, gerando um sentimento de exclusão e impotência nos pais e nos filhos de famílias que não podem adquirir o produto.

A questão da tecnologia é presente, principalmente em três anúncios: Os Mixels (jogo on-line) e os dois comerciais da Fisk (escola de idiomas). Em 
ambos, há necessidade de ter aparelhos eletrônicos, como tablets e celulares, para consumir o produto oferecido. Martineli e Moína (2009) enfatizam que as mídias eletrônicas portáteis têm sido ressignificadas estrategicamente pelo marketing, adquirindo novos significados para as crianças. O celular, por exemplo, não é simplesmente um aparelho com função de mediar a comunicação via voz entre duas pessoas; é, na verdade, uma espécie de "emblema de classe".

Em relação à necessidade dos aparelhos para consumir, existem duas nuances a serem consideradas: o direcionamento da peça às crianças que têm os aparelhos eletrônicos, despertando nelas o desejo de consumir o produto oferecido, estratégia que leva ao "fator amolação" (ou nag fator), ou seja, insistir para que os pais deem o produto (Linn, 2006); e existe também o lado da criança que não tem os aparelhos. Neste caso, mais uma vez, é despertado o desejo, porém seguido da frustração pela impossibilidade de realizá-lo e não poder se divertir, ou aprender inglês. Assim, há a possibilidade do despertar de um sentimento de exclusão. O convite feito ao fim do anúncio do jogo on-line ("Quer jogar?”) ilustra, de forma bastante explícita, esse ponto.

Outros temas são importantes de se destacar, como o desdenho do personagem principal da propaganda da escola de inglês Yázigi em relação ao conhecimento dos outros personagens que nunca foram à Flórida. No mesmo anúncio, há também a frase final: "Yázigi, você cidadão do mundo", marcando mais ainda a exclusão do que não pode consumir o produto oferecido e a posição de poder designada ao que consome. É vendido o status de "cidadão do mundo". Seguindo a mesma lógica, a propaganda da escola de idiomas Fisk finaliza o anúncio da seguinte forma: "Criança que fala Fisk, fala tudo!". Pela análise desses trechos, fica nítido o caráter de aparência (Debord, 1997) das mercadorias oferecidas.

Por fim, como questão que se destaca também como forma de exclusão, está a propaganda da loja de brinquedos Ri Happy e a estratégia de associação do consumidor com um campeão. Principalmente na mensagem visual, em que as crianças que jogam no time do mascote da loja são as que podem ter brinquedos da Ri Happy. Essas crianças que consomem os produtos da loja são retratadas como as que fazem parte do "time campeão". Dessa forma, todos os anúncios dessa categoria, por diferentes estratégias, apresentam o consumo como forma de inclusão, como forma de obter status.

\subsection{Reprodução de papéis de gênero}

As peças apresentadas nesta categoria, em sua maior parte, são direcionadas aos pais, utilizando a criança como personagem. Quando buscam atingir diretamente o público infantil, personagens, que podem ou não ser a própria criança, são utilizados. As propagandas localizadas nesta categoria reforçaram 
papéis de gênero disseminados socialmente ao longo do tempo: a mulher como detentora de um "mundo cor-de-rosa", feminino e delicado, mãe, cuidadora e responsável pelas tarefas domésticas; e o homem como corajoso, inteligente, esperto, rápido e dotado de extrema masculinidade.

Acaba se "colando" o conceito de sexo ao de gênero, impossibilitando que meninas se identifiquem a produtos ditos exclusivos para meninos e vice-versa. Tal fato reforça padrões e papéis de gênero, fazendo com que, desde muito pequenas, as crianças apreendam, de modo não crítico, as divisões, expectativas e rótulos reproduzidos na sociedade sobre o que uma menina ou menino, pautados em seu sexo biológico, devem fazer (Butler, 2003; Jesus, 2012), com o que devem brincar e como devem se comportar como crianças e depois de adultos.

Por conta do nítido direcionamento (em alguns comerciais, mais voltados aos adultos e, em outros, às crianças) e estratégias centrais ao reproduzir esse discurso, as peças desta categoria foram agrupadas em duas subcategorias: "apelo à mãe moderna como responsável pelo cuidado dos filhos" e "meninas X meninos: estereótipos de gênero”. Na figura 3, são apresentados trechos das propagandas analisadas nesta categoria e sua relação com as respectivas subcategorias de análise.

Figura 3 - Trechos das peças analisadas e relação com as subcategorias de análise relacionadas à categoria 3.2 (enumeração de peças referente à figura 1)

\begin{tabular}{|c|c|c|}
\hline PECCA & DESCRICWAO E TRECHOS ANALISADOS & CATEGORIA \\
\hline 14 & $\begin{array}{l}\text { "Danoninho meio a meio com novos sabores: uva roxa e uva verde; banana e aveia e mel. Nutritivo e } \\
\text { muito gostoso!". }\end{array}$ & 3.2 .1 \\
\hline 15 & $\begin{array}{l}\text { A cena inicial exibe mão e filha brincando de se esconder. Narração de um médico apresentando o } \\
\text { produto: "E incrivel o que uma criança inteligente é capaz de fazer. O cérebro do seu filho se desenvolve } \\
\text { até } 85 \% \text { nos primeiros cinco anos de vida. Chegou o Enfagrow, que contém DHA, Colina, Ferro, Iodo } \\
\text { e Zinco: importantes para o desenvolvimento cerebral. "[... "Enfagrow: com nutrientes que alimentam } \\
\text { o incrivel poder de aprender.". }\end{array}$ & 3.2 .1 \\
\hline 16 & $\begin{array}{l}\text { A cena inicial mostra crianças se divertindo em um jardim colorido enquanto a mãe os serve suco. Um } \\
\text { coro canta: "Preparou, bebeu, fac! Também vem fazer do seu jeito! Deixa tudo mais gostoso pro. } \\
\text { veráo perfeito! [...]. }\end{array}$ & 3.2.1 \\
\hline 17 & $\begin{array}{l}\text { "A pele do meu bebé é a mais sucve e delicada. Por isso procuro uma fralda que ofereça incrivel } \\
\text { sucvidade para protege-lo. Pampers Premium Care: oferece ao seu bebe uma proteção cinco estrelas. } \\
\text { [...] Para manter a pele do seu bebê confortóvel e protegida como se não estivesse usando fralda. [...] } \\
\text { Pampers Premium Care: amor, sonhos e brincadeiras. } P \& G . " \text {. }\end{array}$ & 3.2.1 \\
\hline 18 & $\begin{array}{l}\text { Animação: uma fada, com sua varinha, ajuda cavaleiro a capturar dragão [...] Garoto desenhando o } \\
\text { dragão ao lado de sua mãe enquanto ela prepara o produto com uma colher em formato de varinha } \\
\text { mágica. "Chegou Nutren Kids: é rico em cálcio, ferro, zinco, vitaminas e minerais. E o único que já } \\
\text { vem com Leite Ninho e aquele toque mágico de mãe, que acompanha o seu filho mesmo quando você } \\
\text { está longe. Nutren Kiás, o seu toque mágico de nutriçáa. ". }\end{array}$ & 3.2.1 \\
\hline 19 & $\begin{array}{l}\text { Na cena, vários meninos estão em um acampamento e surge um monstro. Aparece um garoto com } \\
\text { acessórios do Ben } 10 \text { para salvar a todos. "Os produtos são com a gente. Salvar o dia é com você. } \\
\text { Nova línha de produtos do Ben } 10 \text { : já nas lojas!". }\end{array}$ & 3.2 .2 \\
\hline 20 & $\begin{array}{l}\text { Um coro de meninas vestidas de cozinheiras num ambiente cor-de-rosa animadas exibindo o brinquedo } \\
\text { anunciado: "Novas Cupcake Surpresa! ". Cantam: "Quem já conhecia não vai acreditar! Seis novas } \\
\text { amiguinhas acabaram de chegar [...] são as novas Cupcake Supresa! Cupcake Surpresa!" }\end{array}$ & 3.2 .2 \\
\hline 21 & $\begin{array}{l}\text { A tela exibe imagens dos produtos anunciados e o logotipo da marca: "Moda é diversão! Veja a nova } \\
\text { colecão e divirta-se em: picadillypfg.com br. Picadilly For Girls: fun confort!" }\end{array}$ & 3.2 .2 \\
\hline
\end{tabular}

Fonte: elaborado pelas autoras. 


\subsubsection{Apelo à mãe moderna como responsável pelo cuidado dos filhos}

Nesta subcategoria, são apresentadas propagandas com mensagens publicitárias que apelam à condição de cuidadora que é atribuído socialmente à mãe, sendo voltadas diretamente a elas. A criança é utilizada como personagem. O discurso é do produto como um mecanismo compensatório prático e rápido para a falta e a distância da mãe que trabalha e não pode estar o tempo todo ao lado do filho, o que implicitamente pode ser compreendido como uma reprodução de que estar sempre com a criança seria sua obrigação como mãe e mulher.

O primeiro ponto a ser explicitado nesta categoria é que todos os anúncios tratam de produtos alimentícios ou relacionados à higiene e cuidados pessoais das crianças. Esse fato, quando analisado em conjunto ao direcionamento das mensagens (às mães), acaba reproduzindo o discurso de gênero, muito discutido por Butler (2003) em sua obra, que as impõe o lugar de cuidadoras, responsáveis pela alimentação, higiene e zelo de seus filhos. Tudo isso é apresentado de forma associada à promessas de nutrição, saúde, praticidade e rapidez, que deve ser cumprida pela própria mãe.

As estratégias que designam o papel de cuidadora à mãe são derivadas de uma lógica de gênero que Butler (2003) descreve como culturalmente construída. A mulher devia dedicar-se aos afazeres domésticos e ao cuidado dos filhos, o que é reproduzido até os dias atuais, mesmo com tantas mudanças sociais e emancipações políticas feministas.

É importante ressaltar que a figura apresentada é a de uma mãe moderna e "multifuncional", que cumpre diversas jornadas durante o dia, assumindo, com sucesso, os diversos papéis que lhe são atribuídos socialmente: trabalhadora, mulher, mãe e cuidadora. Isso, além de reproduzir a lógica patriarcal na Contemporaneidade, idealiza um novo padrão de mulher que, além de cumprir o papel de mãe, deve desempenhar ainda outros.

Um tipo de apelo em especial pode ser claramente notado nos anúncios dos compostos lácteos (Nutren Kids e Enfagrow) e da fralda (Pampers), sendo apresentado com o mesmo elemento básico: a oferta do produto como mecanismo compensatório a um possível sentimento de falta da mãe contemporânea, que deve ter outros afazeres e não pode passar o dia todo ao lado do filho. Esse apelo é muito forte no âmbito visual dos três anúncios, pois, em todos, a imagem passada é do padrão de uma mãe carinhosa e presente, sempre aparecendo ao lado do filho, brincando, sorrindo, cuidando e protegendo a criança. Porém as roupas das mães que são personagens dos anúncios remetem a um ambiente empresarial, a uma mulher que trabalha fora de casa. Esse aspecto fortalece o novo lugar de cuidadora e trabalhadora reservado à mãe, reproduzindo nela 
sentimentos conflitantes, pois acaba se sentindo culpada pela negligência aos cuidados da família e do lar. Nas propagandas, isso pode ser compensado pela aquisição do produto. Assim, utilizando-o, a mãe pode cumprir seus demais afazeres.

Verbalmente falando, esse tipo de apelo é mais forte no anúncio de Nutren Kids: "É o único que já vem com Leite Ninho e aquele toque mágico de mãe, que acompanha o seu filho mesmo quando você está longe. Nutren Kids, o seu toque mágico de nutrição". No mesmo anúncio, a mãe que oferece o produto à criança é, o tempo todo, comparada a uma fada (a colher com que o produto é preparado é em formato de varinha mágica) que "faz mágica" para cuidar do filho quando ele necessita (na animação inicial, a mãe aparece como a fada que ajuda o filho a capturar um dragão), mexendo com o imaginário da criança e com os significados da própria mãe, reforçando ainda mais seu papel atribuído socialmente.

A ideia dos produtos como fonte de nutrição e de saúde também se repete bastante nos comerciais de Nutren Kids, Enfagrow e Danoninho. Todos esses produtos fazem promessas milagrosas de oferecer nutrição instantânea aos filhos ("Enfagrow: nutrientes que alimentam o incrível poder de aprender." "Nutren Kids, o seu toque mágico de nutrição." "Danoninho [. . .]. Nutritivo e muito gostoso! Da infância para toda a vida."). Ainda no anúncio de Enfagrow, a imagem da criança que consome o produto é aliada à inteligência e esperteza. Há também um médico narrando os benefícios do produto, o que ilustra o fato de a criança ter se tornado objeto de várias áreas do saber (Castro, 1998; Pereira \& Souza, 1998).

Já no anúncio dos sucos Tang, apesar de a mensagem não ser diretamente direcionada à mãe, esta aparece no vídeo como personagem, novamente no papel de cuidadora. Ela está sempre sorridente em meio a um clima de verão, festa e diversão, oferecendo o produto às crianças e proporcionando a elas todo o prazer e alegria retratados no momento.

\subsubsection{Meninas $\mathrm{X}$ meninos: estereótipos de gênero}

Nesta categoria, os produtos são voltados diretamente às crianças, sendo elas as protagonistas dos anúncios. Estes são apresentados de forma a gerar uma identificação da criança por meio de seu sexo, reproduzindo estereótipos de feminino e masculino. No anúncio de produtos estereotipados como masculinos, apenas meninos aparecem, negligenciando uma possível identificação de uma 
menina com o produto, e vice-versa. Assim, os anúncios reproduzem ideias do que meninas ou meninos devem se apropriar.

Tais estereótipos de gênero reproduzidos e cristalizados são baseados nos papéis de gênero moldados socialmente, atribuindo a homens e mulheres como devem se comportar e o que devem fazer. Os estereótipos são então a forma mais cômoda e instantânea de padronizar seres humanos, seus comportamentos e valores. Organizar o mundo se baseando em estereótipos ajuda a sociedade a explicar, justificar as relações que são construídas (Oliveira, 2008).

Nos comerciais direcionados às meninas (Cupcake Surpresa e Picadilly), vozes femininas suaves e delicadas são utilizadas para narração. $\mathrm{O}$ direcionamento é claro em ambos os anúncios: em um, pelo próprio nome da linha de um dos produtos: "Picadilly for girls", que significa "Picadilly para meninas", quando traduzido para o português; e no outro (Cupcake Surpresa), pelo fato de que só meninas aparecem no comercial.

O uso de um estereótipo do gênero feminino reproduzido pela sociedade pode ser observado pelo próprio conceito do brinquedo anunciado (Cupcake Surpresa), em que há uma associação entre cozinhar e brincar de boneca. As meninas, em um cenário marcado pelo cor-de-rosa, estão vestidas de cozinheiras e se divertem imensamente durante todo o vídeo.

Assim, a contribuição para a manutenção da legitimação do que a menina deve gostar, apenas por ser menina, fica clara. Isso reforça a posição explicitada na subcategoria anterior, da mulher como cuidadora dos filhos e do lar. De forma reflexa, não há espaço para que meninos se identifiquem com o produto, pois gênero e sexo são apresentados como categorias inseparáveis.

No anúncio da Picadilly, esse mesmo aspecto de legitimação de estereótipo de gênero é notado quando é feita a afirmação: "Moda é diversão!". O que induz à a ideia de que moda significa diversão para meninas. Considerando o nome da linha ("Picadilly para meninas"), também é impossibilitada uma possível identificação de meninos com produto.

Já o anúncio dos Produtos Ben 10 é voltado ao público de meninos, também empregando os estereótipos legitimados como masculinos para chamar a atenção. Isso pode ser observado pelo fato de apenas meninos aparecem no comercial e pela própria narrativa apresentada: um menino (vestindo roupas do personagem, como se o incorporasse) salva seus amigos de um monstro que surge no acampamento. Dessa forma, o produto promete, implicitamente, fazer com que o menino consiga ser forte e corajoso como o personagem, e assim poder salvar o dia ("Os produtos são com a gente. Salvar o dia é com você”). São 
esses elementos que definem o estereótipo de masculinidade reproduzido pela sociedade: o homem que precisa ser viril, forte, herói.

Assim, apesar das diferenças entre os produtos e suas propostas, os comerciais utilizam o discurso estereotipado de gênero masculino e feminino para chamar atenção de meninos e meninas respectivamente, confundindo a ideia de gênero com a de sexo (Butler, 2003). Esse fato colabora com a manutenção desses estereótipos na sociedade, implantando-os nas crianças, pois estas estão construindo seu senso crítico para questionar padrões. Vive-se então uma espécie de "infância midiática", em que o mercado constrói, produz as experiências e significados infantis (Buckingham, 2007).

\section{CONSIDERAÇÕES FINAIS}

Pela revisão bibliográfica realizada, é nítida a constatação a respeito da centralidade do consumo na sociedade atual. Fica claro também o papel de consumidora reservado à criança. A publicidade televisiva infantil acaba então utilizando-se de toda a vulnerabilidade em que o público infantil se encontra, implantando ou evidenciando desejos que somente podem ser satisfeitos pelo consumo.

Essa lógica é explicitada pelos resultados e categorização da publicidade do canal infantil analisado. Os discursos que mais se repetiram foram: "felicidade e status através do consumo", em que o produto é apresentado como fórmula para a felicidade, e "reprodução de papéis de gênero", em que as peças publicitárias reforçam papéis de gênero socialmente construídos mediante a estratégia de exposição de seus produtos.

Ambas as categorias foram divididas em duas subcategorias, por conta de seus diferentes direcionamentos e estratégias: a primeira, em "fantasia e diversão instantânea”, em que as estratégias se baseiam no lúdico e na ideia de rapidez, e "poder e exclusão", em que o produto é oferecido como forma de obter status, evidenciando aspectos de exclusão; e a segunda em "apelo à mãe moderna como responsável pelo cuidado dos filhos", em que as peças são voltadas à mãe e esta é compreendida como cuidadora dos filhos, e os produtos aparecem como forma de compensar sua falta, a falta da mãe que "tem" de trabalhar fora de casa, e "meninas X meninos: estereótipos de gênero", em que as peças são direcionadas às crianças, segmentando brinquedos de meninos e meninas.

Todos os discursos apresentam uma lógica que pode ser compreendida até mesmo como perversa, criando um desejo ou um evidenciado um sentimento de falta, para, em seguida, apresentar a solução por meio da compra do produto. A 
publicidade invade o psiquismo infantil, ainda em formação, para o manipular em benefício próprio, criando uma relação assimétrica entre anunciante o comprador. As teorias psicológicas do desenvolvimento afirmam que, apenas a partir dos 12 anos de idade, a criança forma estruturas mentais semelhantes às dos adultos, não tendo ainda aparatos necessários para julgar de forma crítica as mensagens (CFP, 2008).

Assim, o público infantil tende a absorver os discursos da publicidade como parte da realidade, sendo persuadido a se comportar de forma consumista para satisfazer seus supostos desejos, influenciado os hábitos de consumo da família que detém o poder de compra.

Sendo claro o caráter abusivo da publicidade televisiva voltada para crianças e seu poder de influência ao consumismo infantil, existem aparatos jurídicos em relação ao assunto. A Resolução no 163 , de 13 de março de 2014, do Conanda, por exemplo, considera ilegais quaisquer formas de comunicação mercadológica voltadas ao público infantil, inclusive a publicidade televisiva.

Mesmo com a resolução aprovada no decorrer desta pesquisa, os posicionamentos ativos do CFP e a decisão jurídica tomada em 2016, que condena a publicidade infantil como abusiva e ilegal, continuam sendo veiculadas mensagens publicitárias na televisão e em outros veículos midiáticos. Torna-se evidente a complexidade dos jogos de poder mercadológicos, enfatizando a necessidade de uma melhor fiscalização e de ações governamentais que estimulem pesquisas sobre o tema. Seria então possível coletar ainda mais informações que possam contribuir para medidas adequadas ao contexto brasileiro.

Além da ação que envolveria a restrição ou proibição de veiculação de publicidade infantil, existem outros tipos de medidas preventivas, já implementadas em outros países, que poderiam trazer benefícios, como a inserção da educação para as mídias na grade curricular de ensino. Mesmo o CFP (2008), que apoia as atitudes restritivas, enfatiza a importância de ações que eduquem para o consumo consciente.

Assim, considerando que os jogos de poder envolvidos na temática da publicidade infantil, que dificultam a aprovação de sua proibição a curto prazo, açôes preventivas, como a educação para as mídias, seriam uma ideia viável. Aplicadas de modo contextualizado, evitariam o preocupante crescimento do consumismo infantil, questão que pode gerar inúmeras consequências negativas ao longo do desenvolvimento biopsicossocial. 


\section{REFERÊNCIAS}

Apelação 0342384- 90.2009.8.26.0000, voto no 1927. (2013, 8 maio). Tribunal de Justiça do Estado de São Paulo. $7^{\text {a }}$ Câmara do Direito Privado. Relator: Ramon Mateo Júnior. Recuperado a partir de http://tj-sp.jusbrasil. com.br/jurisprudencia/116137393/apelacao-apl-3423849020098260000sp-0342384-9020098260000/inteiro-teor-116137403

Ariès, P. (2006). História social da criança e da família. (2a ed.). Rio de Janeiro: LTC.

Bauman, Z. (1999). Globalização: as consequências humanas. Rio de Janeiro: Zahar.

Bauman, Z. (2001). Modernidade líquida. Rio de Janeiro: Zahar.

Bauman, Z. (2008). Vida para consumo: a transformação das pessoas em mercadoria. Rio de Janeiro: Zahar.

Brasil. Ministério do Meio Ambiente. (2014). Consumismo infantil: na contramão da sustentabilidade. Instituto Alana (colaborador). Brasília: Ministério do Meio Ambiente. (Cadernos de Consumo Sustentável). Recuperado a partir de http://criancaeconsumo.org.br/wp-content/uploads/2014/05/ConsumismoInfantil.pdf

Brasil. Superior Tribunal de Justiça. (2016). Segunda turma mantém condenação de empresa por publicidade infantil indevida. Brasília: STJ. Recuperado a partir de http://www.stj.jus.br/sites/STJ/default/pt_BR/ Comunica $\%$ C3\%A7\%C3\%A3o/Not\%C3\%ADcias/Not\%C3\%ADcias/ Segunda-Turma-mant\%C3\%A9m-condena\%C3\%A7\%C3\%A3o-deempresa-por-publicidade-infantil-indevida.

Buckingham, D. (2007). Crescer na era das midias eletrônicas. São Paulo: Loyola.

Butler, J. P. (2003). Problemas de gênero: feminismo e subversão da identidade. Rio de Janeiro: Civilização Brasileira.

Capparelli, S., Albuquerque F., Kieling C., Marino, P., Santos, S., Santos, P. T., . . . Balsemão, R. P. (2007). A proteção à infância e à televisão em oito países. Porto Alegre: Caprelli. Recuperado a partir de http://www.capparelli.com.br/ direitos.php 
Castro, L. R. (1998). Uma teoria da infância na contemporaneidade. In S. J. Souza (Org.), Infância e adolescência na cultura do consumo. (pp. 16-43). Rio de Janeiro: Nau.

Conselho Federal de Psicologia. (2008). Contribuição da Psicologia para o fim da publicidade dirigida à criança. Brasília: CFP. Recuperado a partir de http://site. cfp.org.br/wp-content/uploads/2008/10/cartilha_publicidade_infantil.pdf.

Conselho Federal de Psicologia (2014). Publicidade infantil: autorregulação ou restrição? In Notícias. Brasília: CFP. Recuperado a partir de http://site.cfp.org. br/publicidade-infantil-autorregulacao-ou-restricao/.

Conselho Federal de Psicologia (2015). CFP participa de audiência pública que discute restrição à publicidade infantil. Brasília: CFP. Recuperado a partir de http://site.cfp.org.br/cfp-participa-de-audiencia-publica-que-discuterestricao-a-publicidade-infantil/.

Conselho Nacional de Autorregulamentação Publicitária (2013). Missão. São Paulo: Conar. Recuperado a partir de http://www.conar.org.br.

Constituição da República Federativa do Brasil de 1988. (1988, 5 de outubro). Recuperado a partir de http://www.planalto.gov.br/ccivil_03/Constituicao/ Constituicao.htm

Debord, G. (1997). A sociedade do espetáculo. Rio de Janeiro: Contraponto.

Dexheimer, C., \& Bacha, M. L. (2011). O consumismo infantil: A influência das crianças na decisão de compra dos pais. In Anais, 7 Jornada de Iniciação Cientifica, São Paulo. (p. 2). São Paulo: Universidade Presbiteriana Mackenzie.

Fonseca, M. J. V. (2014). O sistema jurídico brasileiro perante uma publicidade direcionada ao público infantil. Revista Jurídica Unifacs, 171, 4-9.

Galindo, D., \& Assolini, P. J. (2008). Eatertainment: a divertida publicidade que alimenta o público infantil. In Anais, 11 Congresso Latinoamericano de Investigadores de la Comunicación, Cidade do México. Monterrey: Instituto Tecnológico y de Estúdios Superiores de Monterrey.

Giacomini Filho, G. (1992). Propaganda e sua sociorregulamentação. In F. A. M. Fernandes \& L. M. Barros (Orgs.), Comunicação e solidariedade. São Paulo: Loyola.

Instituto Alana. (2014). Entenda a resolução que define a abusividade da publicidade infantil. São Paulo: Criança e Consumo. Recuperado a partir de 
http://criancaeconsumo.org.br/noticias/entenda-a-resolucao-que-define-aabusividade-da-publicidade-infantil/

Jesus, J. G. (2012). Orientaçôes sobre identidade de gênero: conceitos e termos: guia técnico sobre pessoas transexuais, travestis e demais transgêneros, para formadores de opinião. Brasília: Edição do autor. Recuperado a partir de https://issuu.com/ jaquelinejesus/docs/orienta_es_popula_o_trans.

Lei Federal no 8.069, de 13 de julho de 1990. (2016, 13 julho). Dispõe sobre o Estatuto da Criança e do Adolescente. Recuperado a partir de http://www. planalto.gov.br/ccivil_03/LEIS/L8069.htm.

Lei Federal no 8.078, de 11 de setembro de 1990 (1990, 11 setembro). Dispóe sobre a proteção do consumidor e dá outras providências. Recuperado a partir de http://www.planalto.gov.br/ccivil_03/leis/18078.htm.

Linn, S. (2006). Crianças do consumo: a infância roubada. São Paulo: Instituto Alana.

Martineli, F. \& Moína, A. (2009). Comunicação, consumo e entretenimento no universo infantil: o celular como telefone ou brinquedo? In V. Veet (Org.), Infância \& consumo: estudos no campo da comunicação. (pp. 59-70). Brasília: Instituto Alana e ANDI.

Oliveira, L. \& Real, E. (2011). Publicidade, consumo e comportamento infantil. In Anais, 13 Congresso de Ciências da Comunicação na Regiāo Nordeste, Maceió. (pp. 4-7). Maceió: Intercom - Sociedade Brasileira de Estudos Interdisciplinares da Comunicação.

Oliveira, S. (2008). Texto visual, estereótipos de gênero e o livro didático de língua estrangeira. Trabalhos em Linguistica Aplicada, 47(1), 91-117. Recuperado a partir de http://dx.doi.org/10.1590/S0103-18132008000100006

Pêcheux, M. (2002). O discurso: estrutura ou acontecimento. (3a ed.). Campinas: Pontes.

Pereira, R. M. R., Cerdeira, A., Andreiuolo, B., \& Souza, S. J. (2005). Ladrōes de sonhos e sabonetes: sobre os modos de subjetivação da infância na cultura do consumo. In S. S. Jobim (Org.), Subjetividade em questão: a infância como crítica da cultura. (pp. 99-117). Rio de Janeiro: 7 Letras. 
Pereira, R. M. R. \& Souza, S. J. (1998). Infância, conhecimento e contemporaneidade. In K. Sonia, \& L. M. Isabel (Orgs.), Infância e produção cultural. (pp. 25-43). Campinas: Papirus.

Pochmann, M. (2014). O mito da grande classe média: capitalismo e estrutura social. São Paulo: Boitempo.

Resolução Conanda no 163, de 13 de março de 2014. (2014, 13 março). Dispõe sobre a abusividade do direcionamento de publicidade e de comunicação mercadológica à criança e ao adolescente. Recuperado a partir de https://www. legisweb.com.br/legislacao/?id=268725.

Salgado, R. G., Pereira, R. M. R., \& Souza, S. J. (2005, janeiro-abril). Pela tela, pela janela: questôes teóricas e práticas sobre infância e televisão. Cadernos Cedes, 25(65), 9-24.

Sampaio, I. S. V. (2004). Televisão, publicidade e infância (2a ed.). São Paulo: Annablume.

Sampaio, I. S. V. (2009). Publicidade e infância: uma relação perigosa. In V. Veet (Org.), Infância \& consumo: estudos no campo da comunicação. (pp. 9-22). Brasília: Instituto Alana e ANDI.

Santos, I. M. (2010). A cultura do consumo e a erotização na infância. Extraprensa, 1(4), 1-20. Recuperado a partir de https://doi.org/10.11606/ extraprensa2009.74369

Sarmento, M. J. (2003). Imaginário e culturas da infância. Cadernos de Educação, 12(21), 51-69.

Silva, W. P. \& Leite, I. N. (2013). A influência da mídia televisiva sobre o processo de formação infantil. In Anais, 5 Fiped - Fórum Internacional de Pedagogia, Vitória da Conquista. (Vol. 1, pp. 1-2). Vitória da Conquista: Universidade Estadual do Sudoeste da Bahia. Recuperado a partir de http:// www.editorarealize.com.br/revistas/fiped/trabalhos/Trabalho_Comunicacao_ oral_idinscrito_1407_a2fa101d1f71a69ad8dce84f753cd57c.pdf

Vigotski, L. S. (2014). Imaginação e criação na infância. São Paulo: Ática. 